\title{
PERBANDINGAN TINGKAT KELELAHAN PADA PASIEN DIABETIC KIDNEY DISEASE DAN HYPERTENSIVE KIDNEY DISEASE YANG MENJALANI HEMODIALISA
}

\author{
Dewi Astri Yulianti, Fiora Ladesvita \\ Program Studi Keperawatan, Fakultas Ilmu Kesehatan \\ Universitas Pembangunan Nasional Veteran Jakarta
}

\begin{abstract}
ABSTRAK
Penyebab yang paling umum dari Gagal ginjal kronik adalah diabetes melitus dan hipertensi. Pasien gagal ginjal kronik akibat hipertensi ataupun diabetes melitus menjalani hemodialisa sebagai terapi penggantian fungsi ginjal. Hemodialisa dijalani oleh pasien gagal ginjal kronik dengan GFR $<15$ $\mathrm{ml} / \mathrm{menit} / 1,73 \mathrm{~m} 2$. Salah satu efek samping akibat hemodialisa yang dijalani pasien adalah kelelahan. Penelitian ini bertujuan untuk membandingkan tingkat kelelahan pasien gagal ginjal yang disebabkan oleh diabetes melitus dengan pasien gagal ginjal yang disebabkan oleh hipertensi di komunitas Klub Perawatan Ginjal Indonesia. Desain penelitian ini adalah deskriptif analitik dengan pendekatan cross sectional. Sampel dalam penelitian ini berjumlah 52 responden. Hasil analisis menunjukkan tidak ada perbedaan tingkat kelelahan pada pasien penyakit ginjal diabetik dan hipertensi yang menjalani hemodialisis ( $\mathrm{p}$ value $=0,187$ ). Selain itu, diperoleh tidak ada hubungan antara karakteristik pasien yang meliputi umur, jenis kelamin, pendidikan, pekerjaan dan kadar hemoglobin dengan tingkat kelelahan, ( $p$ value $>0,05)$.
\end{abstract}

Kata Kunci : Hemodialisis, Kelelahan, Diabetes Melitus, Hipertensi, Gagal Ginjal Kronis.

\begin{abstract}
The most common causes of chronic kidney disease were diabetes mellitus and hypertension. Patients with chronic kidney disease due to hypertension or diabetes mellitus undergo hemodialysis as renal function replacement therapy. Hemodialysis was undertaken by patients with chronic kidney disease with a GFR $<15 \mathrm{ml}$ / minute / $1.73 \mathrm{~m} 2$. One of the side effects of hemodialysis that the patient undergoes was fatigue. This study aims to compare the fatigue level of patients with kidney disease caused by diabetes mellitus with patients with kidney failure caused by hypertension in the Indonesian Kidney Care Club community. This research design was descriptive analytic with cross sectional approach. The sample in this study amounted to 52 respondents. The results of the analysis showed that there was no difference in the level of fatigue in patients with diabetic kidney disease and hypertension who underwent hemodialysis ( $p$ value $=0.187$ ). In addition, it was found that there was no relationship between patient characteristics including age, sex, education, occupation and hemoglobin levels with fatigue levels, ( $p$ value>0.05).
\end{abstract}

Keywords : Chronic Kidney Disease; Diabetes Melitus; Fatigue; Hemodialysis; Hypertensive

Alamat korespondensi: Fakultas Ilmu Kesehatan, Universitas Pembangunan Nasional Veteran Jakarta, Jalan Limo Raya Kelurahan Limo Kecamatan Limo Kota Depok Kode Pos 16515

Email: fiora.ladesvita@upnvj.ac.id

\section{PENDAHULUAN}

Gagal ginjal kronik adalah masalah kesehatan yang menyerang fungsi ginjal sehingga mengalami penurunan dan tidak dapat diperbaiki seperti sedia kala (Black, 2014). Gagal ginjal kronik adalah suatu masalah fungsi ginjal progresif sehingga metabolisme dan keseimbangan cairan elektrolit tidak dapat dipertahankan dengan baik oleh tubuh. Salah satu gejala yang timbul saat 
terkena gagal ginjal kronik ialah kelelahan, nantinya akan terjadi gangguan lainnya termasuk anemia kronik akibat dari sel darah merah tidak dapat bertahan lama dan terjadi defisiensi eritroprotein sehingga penderita akan mengalami kelelahan (fatigue) (Maman Indrayana Armayani, 2018).

Menurut World Health Organization (WHO) pada tahun 2016 gagal ginjal masuk urutan ke 8 dari 10 penyakit mematikan di dunia dengan rentang usia 60-69 tahun dan urutan 9 dari 10 penyakit mematikan di negara-negara berpenghasilan tinggi. Prevalensi RISKESDAS di Indonesia angka kejadian gagal ginjal kronik pada tahun 2018 mencapai 3,8\% sedangkan pada tahun 2013 hanya sebesar 2,0\%, berarti terjadi kenaikan 1,8\% pada tahun 2018 ini, menurut diagnosis dokter pada usia $\geq 15$ tahun (RISKESDAS, 2018). Mayoritas penyakit gagal ginjal kronik disebabkan oleh hipertensi dan diabetes mellitus. (Black, 2014) dalam bukunya mengatakan bahwa penyebab gagal ginjal kronik atau CKD adalah diabetes mellitus dengan kejadian sebesar $30 \%$ dan hipertensi merupakan penyebab kedua gagal ginjal kronik. Diabetes mellitus nefropati merupakan penyakit yang umum menyebabkan gagal ginjal, diperkirakan $30 \%$ penderita gagal ginjal kronik stadium 5 memiliki masalah penyakit diabetes mellitus (diabetes mellitus tipe 1 atau diabetes mellitus tipe 2).

Penyebab fatigue pada pasien yang menjalani hemodialisis karena faktor fisiologis, antara lain karena adanya penumpukan sisa hasil metabolisme, nafsu makan yang menurun, dan mengkonsumsi minuman atau makanan energi berlebihan. Selain itu fatigue juga dapat diakibatkan karena reaksi emosional dan aktivitas fisik minimal atau melakukan aktivitas yang sama. (Suparti dkk, 2018). Fatigue juga disebabkan oleh sindrom uremia pada penderita yang menjalani hemodialisa. Uremia menyebabkan kelelahan perifer, yaitu lelah yang diakibatkan karena kerusakan pada sistem saraf perifer sehingga menyerang distal, sistemik, mororik serta sensorik penderita. Kondisi ini mengakibatkan adanya penurunan fungsi saraf motorik dan sensorik dan uremia yang berlebihan dapat menyebabkan dialisa tidak dapat bekerja secara maksimal sehingga masih terdapat ureum yang tertinggal (Nia Khusniyati M , Sri Yona, 2018). Pada dasarnya, pasien dengan diabetes melitus tipe 2 cenderung mengalami kelelahan akibat ketidakefektifan energi yang dihasilkan yang disebabkan oleh resistensi insulin. Sedangkan pada pasien hipertensi, cenderung mengalami kelelahan akibat ketidakseimbangan suplai oksigen dengan kebutuhan. Namun, belum diketahui apakah ada perbedaan tingkat kelelahan antara pasien gagal ginjal yang disebabkan oleh diabetes melitus dengan penyakit gagal ginjal yang disebabkan oleh hipertensi. Tujuan penelitian ini adalah mengetahui perbandingan tingkat kelelahan pada pasien diabetic kidney disease dan Hypertensive kidney disease yang menjalani hemodialisa di Komunitas Indonesia Kidney Care Club.

\section{METODE PENELITIAN}

Penelitian ini menggunakan data kuantitatif dengan metode penelitian yang digunakan yaitu deskripsi analitik dengan pendekatan desain cross sectional. Populasi pada penelitian ini adalah pasien yang menderita diabetic kidney disease dan Hypertensive kidney disease yang menjalani hemodialisa di komunitas Indonesia Kidney Care Club dengan total jumlah sampel yaitu 52 orang, 26 orang dengan diabetic kidney disease dan 26 orang Hypertensive kidney disease. Teknik sampling yang digunakan yaitu total sampling dengan kriteria inklusi pasien gagal ginjal kronik yang menjalani hemodialisa, pasien gagal ginjal yang disebabkan oleh diabetes melitus atau hipertensi, dan bersedia menjadi responden. Kuesioner yang digunakan adalah FACIT (Functional Assesment Chronic Illness Therapy), kuesioner sudah teruji validitas dan realibitasnya. Skor kuesioner FACIT $0-52$. Apabila hasil kuesioner < 30 seseorang dikatakan memiliki tingkat kelelahan yang tinggi (Sihombing \& Dkk, 2016).

\section{HASIL DAN PEMBAHASAN}

Berdasarkan hasil pada tabel 1 pada variabel diabetic kidney disease, pasien gagal ginjal korinik yang memiliki riwayat penyakit penyerta diabetes mellitus sebanyak 26 orang (100\%) dan pada variabel Hypertensive kidney disease, pasien gagal ginjal kronik yang memiliki riwayat penyakit penyerta hipertensi atau tekanan darah tinggi adalah sebanyak 26 orang dengan persentase $100 \%$. 
Tabel 1. Distribusi Frekuensi Responden Berdasarkan Jenis Kelamin, Pendidikan, Dan Pekerjaan, Juni 2020 (n=52)

\begin{tabular}{lcc}
\hline \multicolumn{1}{c}{ Variabel } & Frekuensi & Persentase (\%) \\
\hline Diabetic Kidney Disease & $\mathbf{2 6}$ & $\mathbf{1 0 0}$ \\
\hline Jenis Kelamin & \multicolumn{1}{c}{} \\
1. Perempuan & 21 & 19.2 \\
2. Laki-Laki & & 80.8 \\
\hline Tingkat Pendidikan & 1 & 3.8 \\
1. Tidak Sekolah - SD & 2 & 7.7 \\
2. SMP & 11 & 42.3 \\
3. SMA & 12 & 46.2 \\
4. Perguruan Tinggi & & \\
\hline Pekerjaan & 15 & 57.7 \\
1. Tidak Bekerja/IRT & 2 & 7.7 \\
2. PNS & 9 & 34.6 \\
3. Non PNS/Wiraswasta/ & & \\
$\quad$ Wirausaha & $\mathbf{2 6}$ & $\mathbf{1 0 0}$ \\
\hline Hypertensive Kidney Disease & & 19.2 \\
\hline Jenis Kelamin & 5 & 80.8 \\
1. Perempuan & 21 & 3.8 \\
2. Laki-Laki & & 3.8 \\
\hline Tingkat Pendidikan & 1 & 34.6 \\
1. Tidak Sekolah - SD & 1 & 57.7 \\
2. SMP & 9 & 46.2 \\
3. SMA & 15 & \\
4. Perguruan Tinggi & 12 & \\
\hline Pekerjaan & 3 & \\
1. Tidak Bekerja/IRT & & \\
2. PNS & & \\
3. Non PNS/Wiraswasta/ & & \\
$\quad$ Wirausaha & & \\
\hline
\end{tabular}

Kemudian hasil analisa pada tabel 1 variabel jenis kelamin, tingkat pendidikan dan pekerjaan pada pasien diabetic kidney disease diatas. Untuk variabel jenis kelamin didapatkan hasil bahwa laki-laki paling banyak mengalami diabetic kidney disease yaitu sebanyak 21 orang (80,8\%) sedangkan perempuan sebanyak 5 orang $(19,2 \%)$. Pada tingkat pendidikan didapatkan hasil responden dengan tingkat pendidikan perguruan tinggi dan SMA paling banyak mengalami diabetic kidney disease. perguruan tinggi sebanyak 12 orang (46,2\%), SMA sebanyak 11 orang (42,3\%), SMP sebanyak 2 orang $(7,7 \%)$ dan tidak sekolah-SD sebanyak 1 orang $(3,8 \%)$. Lalu, pada variabel pekerjaan didapatkan hasil responden paling banyak tidak bekerja/IRT sebanyak 15 orang $(57,7 \%)$, Non PNS/Wiraswasta/Wirausaha sebanyak 9 orang $(34,6 \%)$ dan terakhir PNS sebanyak 2 orang $(7,7 \%)$.

Sedangkan hasil pada tabel 1 variabel jenis kelamin, tingkat pendidikan dan pekerjaan pada pasien Hypertensive kidney disease diatas, Untuk variabel jenis kelamin didapatkan hasil bahwa laki-laki paling banyak mengalami Hypertensive kidney disease sebanyak 21 orang (80,8\%) sedangkan perempuan sebanyak 5 orang $(19,2 \%)$. Pada tingkat pendidikan didapatkan hasil responden dengan tingkat pendidikan perguruan tinggi paling banyak mengalami Hypertensive kidney disease. perguruan tinggi sebanyak 15 orang $(57,7 \%)$, SMA sebanyak 9 orang $(34,6 \%)$, SMP sebanyak 1 orang $(3,8 \%)$ dan tidak sekolah-SD sebanyak 1 orang $(3,8 \%)$. Kemudian, pada variabel 
pekerjaan didapatkan hasil responden paling banyak tidak bekerja/IRT sebanyak 12 orang (46,2\%), lalu Non PNS /Wiraswasta /Wirausaha sebanyak 11 orang (42,3\%) dan PNS sebanyak 3 orang $(11,5 \%)$.

Tabel 2 Distribusi Rata-Rata Responden Berdasarkan Usia Dan Hasil Laboratorium Hemoglobin, Juni 2020 (n=52)

\begin{tabular}{lccccc}
\hline \multicolumn{1}{c}{ Variabel } & n & Mean & SD & Min & Max. \\
\hline Diabetic Kidney Disease & & & & & \\
Tingkat Kelelahan & \multirow{2}{*}{26} & 31.88 & 9.206 & 15 & 43 \\
Usia & & 45.65 & 14.068 & 19 & 70 \\
Hemoglobin & 10.36 & 2.064 & 7 & 15 \\
\hline Hypertensive Kidney Disease & & & & & \\
Tingkat Kelelahan & 26 & 34.96 & 8.789 & 11 & 45 \\
Usia & & 40.46 & 12.959 & 19 & 65 \\
Hemoglobin & & 9.53 & 1.479 & 6 & 13 \\
\hline
\end{tabular}

Berdasarkan hasil pada tabel 2 variabel tingkat kelelahan, usia dan hasil laboratorium hemoglobin pada pasien diabetic kidney disease diatas didapatkan rata rata tingkat kelelahan responden diabetic kidney disease yaitu 31,88 (SD = 9,206),dengan nilai kelelahan minimum 15 dan maksimum 43. Rata rata usia responden dengan diabetic kidney disease yaitu 45,65 tahun $(\mathrm{SD}=$ 14,068) dengan usia minimum 19 tahun dan maksimum 70 tahun. sedangkan rata rata hasil hemoglobin responden diabetic kidney disease yaitu 10,36 gr/ $\mathrm{dl}(\mathrm{SD}=2,064)$ dengan $\mathrm{Hb}$ minimum $7 \mathrm{gr} / \mathrm{dl}$ dan $\mathrm{Hb}$ maksimum $15 \mathrm{gr} / \mathrm{dl}$.

Sedangkan hasil pada tabel 2 variabel tingkat kelelahan, usia dan hasil laboratorium hemoglobin pada pasien Hypertensive kidney disease diatas didapatkan rata rata tingkat kelelahan responden Hypertensive kidney disease yaitu 34,96 (SD = 8,789), dengan nilai kelelahan minimum 11 dan maksimum 45. Rata rata usia responden dengan Hypertensive kidney disease yaitu 40,46 tahun $(\mathrm{SD}=12,959)$ dengan usia minimum 19 tahun dan maksimum 65 tahun. kemudian rata rata hasil hemoglobin responden Hypertensive kidney disease yaitu 9,53 gr/dl $(\mathrm{SD}=1,479)$ dengan $\mathrm{Hb}$ minimum $6 \mathrm{gr} / \mathrm{dl}$ dan $\mathrm{Hb}$ maksimum $13 \mathrm{gr} / \mathrm{dl}$.

Tabel 3. Analisa Hubungan Usia dan Hasil Laboratorium Hemoglobin Terhadap Tingkat Kelelahan, Juni 2020 (n=52)

\begin{tabular}{lccc}
\hline \multirow{2}{*}{ Variabel } & \multicolumn{2}{c}{ Tingkat Kelelahan } \\
\cline { 2 - 4 } & $\mathbf{n}$ & r spearman & P value \\
\hline Diabetic Kidney Disease & 26 & -0.133 & 0.518 \\
Usia & & 0.149 & 0.467 \\
Hemoglobin & \multirow{2}{*}{26} & 0.225 & 0.269 \\
\hline Hypertensive Kidney Disease & & 0.114 & 0.579 \\
Usia & &
\end{tabular}

Hasil analisa tabel 3 pada usia pasien DKD terhadap tingkat kelelahan didapatkan hasil $\mathrm{p}$ value $=0,518(\alpha=0,05$ atau 0,01$)$ menandakan variabel tidak signifikan atau tidak ada hubungan usia terhadap tingkat kelelahan pada pasien diabetic kidney disease, tingkat hubungan sangat lemah $(\mathrm{r}$ spearman $=-0,133$ ) dan hubungan kedua variabel tidak searah karena hasil $r$ spearman negatif, jadi dapat disimpulkan semakin bertambahnya usia tingkat kelelahan semakin rendah. Lalu pada hasil 
analisa tabel 10 variabel usia pasien Hypertensive kidney disease terhadap tingkat kelelahan hasil $\mathrm{p}$ value $=0,269(\alpha=0,05$ atau 0,01$)$ menandakan variabel tidak signifikan atau tidak ada hubungan usia dengan tingkat kelelahan pada pasien Hypertensive kidney disease, tingkat kekuatan hubungan sangat lemah $(0,225)$ dan hubungan kedua variabel searah karena hasil $r$ spearman positif, jadi dapat disimpulkan usia terhadap tingkat kelelahan adalah semakin bertambahnya usia tingkat kelelahan semakin tinggi. Penelitian ini tidak sejalan dengan penelitian (Pranandari and Supadm, 2015) yang menyatakan bahwa ada hubungan antara usia dengan pasien gagal ginjal kronik yang menjalani hemodialisa dengan hasil $\mathrm{p}$ value $=0,018(\mathrm{p}<0,05)$. Kemudian pada hasil penelitian (Sulistiowati and Idaiani, 2015) juga memiliki hasil $\mathrm{p}$ value $=0,001$ yang dapat disimpulkan bahwa ada hubungan antara usia dengan masalah kesehatan gagal ginjal kronik. Menurut (Sakitri, Makiyah and Khoiriyati, 2017) pada usia 40 tahun LFG akan mulai mengalami penurunan bertahap sampai usia 70 tahun hingga ginjal hanya dapat berfungsi $50 \%$ dari semestinya sehingga dapat menyebabkan kelelahan. Usia pada penderita yang menjalani hemdialisa diukur dari pasien diatas 18 tahun sampai $>50$ tahun.

Sedangkan pada analisa hasil laboratorium hemoglobin pasien diabetic kidney disease terhadap tingkat kelelahan didapatkan hasil $p$ value $=0,467(\alpha=0,05$ atau 0,01$)$ menandakan variabel tidak signifikan atau tidak ada hubungan hasil laboratorium hemoglobin terhadap tingkat kelelahan pada pasien diabetic kidney diseas, tingkat hubungan sangat lemah (r spearman $=0,149$ ) dan hubungan kedua variabel searah karena hasil $r$ spearman positif, jadi kesimpulan yang dapat diambil pada hasil laboratorium hemoglobin terhadap tingkat kelelahan adalah semakin tingginya nilai hemoglobin tingkat kelelahan semakin tinggi. Pada analisa hasil laboratorium hemoglobin pasien Hypertensive kidney disease terhadap tingkat kelelahan didapatkan hasil $\mathrm{p}$ value $=0,579$ menandakan variabel tidak signifikan atau tidak ada hubungan hasil laboratorium hemoglobin dengan tingkat kelelahan pada pasien Hypertensive kidney disease, tingkat hubungan sangat lemah ( $\mathrm{r}$ spearman $=0,114$ ) dan hubungan kedua variabel searah karena hasil $\mathrm{r}$ spearman positif., jadi dapat disimpulkan bahwa pada hasil laboratorium hemoglobin terhadap tingkat kelelahan adalah semakin tinggi nilai hemoglobin, tingkat kelelahan semakin tinggi. Penelitian ini sejalan dengan penelitian (Hasan and Tirtana, 2019) dengan $p$ value 0,118 dan $r$ spearman -0,133 yang dapat disimpulkan bahwa hubungan antar kedua variabel sangat lemah dan hubungan tidak searah karena hasil $r$ spearman negatif dan variabel dapat diartikan bahwa semakin tinggi nilai $\mathrm{Hb}$ semakin rendah tingkat kelelahan. Menurut (Ifaroifah and Dkk, 2019) anemia atau tidak adekuatnya kadar darah merah dalam tubuh penderita gagal ginjal kronik yang menjalani hemodialisa, hasil hemoglobin yang berada dibawah normal $(10 \mathrm{gr} / \mathrm{dl})$ adalah tanda terjadinya anemia. Anemia terjadi karena eritroprotein yang berkurang karena kerusakan sel peritubular di ginjal atau tingginya kadar urea dan kreatinin akibat lama menjalani terapi hemodialisa. Karena berkurangnya eritroprotein atau $\mathrm{Hb}$ dibawah $10 \mathrm{gr} / \mathrm{dl}$ pada penderita gagal ginjal kronik yang menjalani hemodialisa menyebabkan penderita mengalami anemia sehingga merasakan kelelahan.

Tabel 4. Analisa Hubungan Jenis Kelamin Terhadap Tingkat Kelelahan, Juni 2020 (n=52)

\begin{tabular}{lccc}
\hline \multirow{2}{*}{ Variabel } & \multicolumn{3}{c}{ Tingkat Kelelahan } \\
\cline { 2 - 4 } & $\mathbf{N}$ & Mean Rank & P value \\
\hline Diabetic Kidney Disease & & & \\
Jenis Kelamin & 5 & 14.70 & 0.696 \\
1.Perempuan & 21 & 13.21 & \\
2.Laki-Laki & & & \\
\hline Hypertensive Kidney Disease & 5 & 12.90 & 0.845 \\
Jenis Kelamin & 21 & 13.64 & \\
1. Perempuan & & & \\
2. Laki-Laki & & & \\
\hline
\end{tabular}


Berdasarkan hasil penelitian pada tabel 4, tidak ada hubungan antara jenis kelamin pasien DKD dan HKD terhadap tingkat kelelahan karena hasil $p$ value $>0,05$ ( $p$ value DKD $=0,696$ dan $p$ value $H K D=0,845$ ). Penelitian ini sejalan dengan hasil penelitian (Faizal, M.Nur and Rayasari, 2018) yang memiliki hasil $p$ value $=0,213$ dan menyatakan tidak ada hubungan pada jenis kelamin dengan management self care fatigue. Namun penelitian ini berbeda dengan hasil penelitian (Pranandari and Supadm, 2015) yang memiliki hasil $\mathrm{p}$ value $=0,040$ dan menyatakan ada hubungan antara jenis kelamin dengan masalah kesehatan gagal ginjal kronik yang sedang menjalani terapi hemodialisa. Dari 72 responden terdapat 50 orang berjenis kelamin laki-laki dan 22 orang berjenis kelamin perempuan, laki-laki lebih berisiko tinggi terkena HKD atau DKD. Pada penelitian (Sakitri, Makiyah and Khoiriyati, 2017) jenis kelamin laki-laki banyak yang memiliki masalah kesehatan gagal ginjal kronik karena gaya hidup seperti merokok dan konsumsi alkohol. Jika gaya hidup ini dilakukan terus-menerus akan mengakibatkan masalah kesehatan seperti diabetes mellitus ataupun hipertensi yang akhirnya menyebabkan kelelahan.

Tabel 5. Analisa Hubungan Tingkat Pendidikan dan Pekerjaan Terhadap Tingkat Kelelahan, Juni $2020(n=52)$

\begin{tabular}{|c|c|c|c|}
\hline \multirow{2}{*}{ Variabel } & \multicolumn{3}{|c|}{ Tingkat Kelelahan } \\
\hline & $\mathbf{n}$ & Mean Rank & P value \\
\hline \multicolumn{4}{|l|}{ Diabetic Kidney Disease } \\
\hline \multicolumn{4}{|l|}{ Tingkat Pendidikan } \\
\hline 1.Tidak Sekolah - SD & 1 & 6.50 & \multirow{4}{*}{0.415} \\
\hline 2.SMP & 2 & 7.50 & \\
\hline 3.SMA & 11 & 13.14 & \\
\hline 4.Perguruan Tinggi & 12 & 15.42 & \\
\hline \multicolumn{4}{|l|}{ Pekerjaan } \\
\hline 1.Tidak Bekerja / IRT & 15 & 11.00 & \multirow[t]{3}{*}{0.146} \\
\hline 2.PNS & 2 & 15.75 & \\
\hline 3.Non PNS / Wiraswasta/ Wirausaha & 9 & 17.17 & \\
\hline \multicolumn{4}{|l|}{ Hypertensive Kidney Disease } \\
\hline \multicolumn{4}{|l|}{ Tingkat Pendidikan } \\
\hline 1. Tidak Sekolah - SD & 1 & 6.00 & \multirow{4}{*}{0.304} \\
\hline 2. SMP & 1 & 23.50 & \\
\hline 3. SMA & 9 & 11.44 & \\
\hline 4. Perguruan Tinggi & 15 & 14.57 & \\
\hline \multicolumn{4}{|l|}{ Pekerjaan } \\
\hline 1. Tidak Bekerja / IRT & 12 & 12.46 & \multirow{3}{*}{0.746} \\
\hline 2. PNS & 3 & 16.00 & \\
\hline 3. Non PNS / Wiraswasta / Wirausaha & 11 & 13.95 & \\
\hline
\end{tabular}

Berdasarkan tabel 5, hasil penelitian menyatakan bahwa tidak ada hubungan tingkat pendidikan pada pasien DKD dan HKD dengan tingkat kelelahan karena hasil $p$ value $>0,05$ (hasil $\mathrm{p}$ value DKD 0,415 dan $\mathrm{p}$ value HKD 0,304). Hasil penelitian ini sejalan dengan penelitian (Sulistiowati and Idaiani, 2015) dengan hasil $\mathrm{p}$ value $=0,63$ yang menandakan bahwa tidak ada hubungan antara usia dengan masalah kesehatan gagal ginjal kronik. Lalu pada penelitian (Faizal, M.Nur and Rayasari, 2018) juga mengatakan bahwa tidak ada hubungan tingkat pendidikan dengan management self care fatigue karena nilai $\mathrm{p}$ value $=0,063$. Menurut (Sakitri, Makiyah and Khoiriyati, 2017) pendidikan dapat juga mempengaruhi fatigue, seseorang yang memiliki pendidikan yang 
tinggi dapat berfikir untuk mencari solusi dan tindakan yang tepat atas keadaan yang dideritanya, bagaimana penanganan pada gagal ginjal kroniknya dan mengatasi perasaan lelah yang dialaminya.

Pada hasil penelitian pekerjaan pada pasien DKD dan HKD juga menyatakan bahwa tidak ada hubungan dengan tingkat kelelahan (hasil $p$ value DKD 0,146 dan $p$ value HKD 0,746). Hasil penelitian sama dengan penelitian yang dilakukan (Sulistiowati and Idaiani, 2015) menyebutkan tidak ada hubungan pekerjaan terhadap masalah kesehatan ggk dengan hasil $p$ value $=0,42$. Menurut (Sakitri, Makiyah and Khoiriyati, 2017) pekerjaan juga dapat mempengaruhi kelelahan karena penghasilan dan aktivitas pekerjaan yang dilakukan.

Tabel 6. Analisa Perbandingan Diabetic Kidney Disease dan Hypertensive Kidney Disease Terhadap Tingkat Kelelahan. Juni 2020 (n=52)

\begin{tabular}{lccc}
\hline \multirow{2}{*}{\multicolumn{1}{c}{ Variabel }} & \multicolumn{3}{c}{ Tingkat Kelelahan } \\
\cline { 2 - 4 } & $\mathbf{N}$ & Mean Rank & P value \\
\hline Diabetic Kidney Disease & 26 & 23.73 & \multirow{2}{*}{0.187} \\
Hypertensive Kidney Disease & 26 & 29.27 & \\
\hline
\end{tabular}

Berdasarkan hasil yang didapat dari tabel 6 terkait adakah perbandingan pada variabel independen diabetic kidney disease dan Hypertensive kidney disease terhadap variabel dependen tingkat kelelahan dapat disimpulkan bahwa, tidak ada perbedaan yang signifikan antara tingkat kelelahan pada pasien diabetic kidney disease dengan Hypertensive kidney disease yang menjalani hemodialisa di komunitas Indonesia Kidney Care Club, karena didapatkan hasil $\mathrm{p}$ value = 0,187 $(\mathrm{p}>$ $0,05)$.

Penelitian ini berbanding terbalik dengan hasil penelitian (Hasan and Tirtana, 2019) yang menyatakan ada hubungan antara penyakit penyerta dengan tingkat kelelahan ( $\mathrm{p}$ value $=0,001 / \mathrm{p}$ $<0,05$ ). Kemudian pada penelitian (Masi, Gresty N M, 2018) juga menyimpulkan bahwa ada perbedaan antara penyakit penyerta diabetes mellitus dan hipertensi dengan kualitas hidup pasien gagal ginjal kronik dengan hasil $p$ value $=0,000$. Menurut (Balouchi et al., 2016) setelah seseorang menjalani terapi hemodialisa akan merasakan perasaan lelah antara 60 hingga 97\% dikarenakan lamanya waktu dialisis (4 sampai 5 jam sekali melakukan hemodialisis). Faktor yang dapat menyebabkan kelelahan antara lain adanya uremia, nilai $\mathrm{Hb}$ rendah, penggunaan obat-obatan yang menyebabkan rasa lelah, hemodialisis yang tidak adekuat, cemas dan depresi, kualitas tidur buruk, pemenuhan gizi tidak adekuat. Menurut peneliti kelelahan juga dapat dipengaruhi karena tidak terkontrolnya penyakit penyerta pada pasien gagal ginjal kronik, seperti gula darah yang tidak terkontrol pada pasien diabetes mellitus atau tekanan darah yang tidak terkontrol pada pasien hipertensi.

\section{SIMPULAN}

Dari hasil penelitian, dapat disimpulkan tidak ada perbedaan yang signifikan antara tingkat kelelahan pada pasien diabetic kidney disease dengan Hypertensive kidney disease yang menjalani hemodialisa di komunitas Indonesia Kidney Care Club, karena didapatkan hasil $p$ value = 0,187 $(p>$ 0,05). Selain itu, didapatkan hasil bahwa tidak ada hubungan antara jenis kelamin, usia, tingkat pendidikan, pekerjaan dan hasil laboratorium hemoglobin dengan tingkat kelelahan pada pasien diabetic kidney disease dan Hypertensive kidney disease yang menjalani hemodialisa di komunitas IKCC.

\section{DAFTAR PUSTAKA}

Balouchi, A. Et Al. (2016). Comparison Of Effects Of Orange And Lavender Extract On Fatigue In Hemodialysis Patients. Der Pharmacia Lettre, 8(8), Pp. 50-54.

Black, J. M. Dan J. H. (2014). Keperawatan Medikal Bedah Manajemen Klinis Untuk Hasil Yang 
Diharapkan. Elsevier.

Faizal, K. M., M.Nur, B. And Rayasari, F. (2018). Efektivitas Edukasi Grup Terhadap Management Self Care Fatigue Pada Klien End Stage Renal Disease (Esrd) Yang Menjalankan Hemodialisa. Jurnal Ilmiah Stikes Citra Delima Bangka Belitung, 2. Doi: Https://Doi.Org/10.33862/Citradelima.V2i1.4.

Hasan, M. N. And Tirtana, A. (2019). Hubungan Biochemical Marker Dan Comorbidity Dengan Tingkat Fatigue Pada Klien Hemodialisis Di Yogyakarta Relationship Between Biochemical Marker And Comorbidity With Fatigue In Patients With Hemodialisis In Yogyakarta. 10(2), Pp. 115-122.

Ifaroifah And Dkk. (2019). Relationship Between Hemodialysis And Hb Levels With Level Of Fatigue', International Journal Of Nursing And Midwifery Science (Ijnms), 2(03), Pp. 304-310. Doi: 10.29082/Ijnms/2018/Vol2.Iss03.162.

Maman Indrayana Armayani, W. O. R. (2018). Pengaruh Pursed Lip Breathing Terhadap Fatigue Pasien Ggk Di Ruang Hemodialisa. Health Information : Jurnal Penelitian, 10(2).

Masi, Gresty N M, R. K. (2018). Perbandingan Kualitas Hidup Pasien Gagal Ginjal Kronik Dengan Comorbid Faktor Diabetes Melitus Dan Hipertensi Di Ruangan Hemodialisa Rsup. Prof. Dr. R. D. Kandou Manado. E-Jurnal Keperawatan (E-Kp), 5(April), Pp. 1-9.

Nia Khusniyati M , Sri Yona, I. M. K. (2018). Jurnal Kperawatan Terpadu (Integrated Nursing Journal). 1, Pp. 65-75. Available At: Http://Jkt.PoltekkesMataram.Ac.Id/Index.Php/Home/Index\%0ap-Issn:

Pranandari, R. And Supadm, W. (2015). Faktor Risiko Gagal Ginjal Kronik Di Unit Hemodialisis Rsud Wates Risk Factors Cronic Renal Failure On. 11(2), Pp. 316-320.

Riskesdas. (2018). Riskesdas 2018: Executive Summary.

Sakitri, G., Makiyah, N. And Khoiriyati, A. (2017). Pengaruh Intradialytic Exercise Terhadap Fatigue Pasien Hemodialisis The Effect Of Intradialytic Exercise On Fatigue Hemodialisis Patients At Rsup Dr . Soeradji Tirtonegoro Klaten, 15(1), Pp. 58-64.

Sulistiowati, E. And Idaiani, S. (2015). Faktor Risiko Penyakit Ginjal Kronik Berdasarkan Analisis Cross-Sectional Data Awal Studi Kohort Penyakit Tidak Menular Penduduk Usia 25-65 Tahun Di Kelurahan Kebon Kalapa, Kota Bogor Tahun 2011', Buletin Penelitian Kesehatan, 43, Pp. 163-172. Suparti Dkk, S. (2018). Hubungan Depresi Dengan Fatigue Pada Pasien Hemodialisis. Journal Of Health Studies, 2(1), Pp. 62-74. Doi: 10.31101/Jhes.435. 